\title{
CLOTILDE WILSON, CECIL HEMLEY E A GÊNESE DE PHILOSOPHER OR DOG? (QUINCAS BORBA)
}

\section{HÉLIO DE SEIXAS GUIMARÃES}

Universidade de São Paulo

São Paulo, São Paulo, Brasil

\section{VINICIUS FERNANDES DE OLIVEIRA}

Universidade de São Paulo

São Paulo, São Paulo, Brasil

Resumo: Este artigo trata da primeira tradução de Quincas Borba para o inglês, publicada em 1954 com o título Philosopher or Dog?, por meio do exame da correspondência da tradutora Clotilde Wilson com a editora Noonday Press, especialmente com seu editor Cecil Hemley. O material traz informações inéditas sobre a professora, crítica e tradutora, cujo nome está associado e de certa forma acabou obscurecido pelo curioso título dado à edição norte-americana de Quincas Borba. Além de recompor seu processo de tradução e publicação, o objetivo é situá-la no contexto das edições dos romances de Machado de Assis publicadas na década de 1950, para compreender melhor as condições que propiciaram o lançamento, em anos consecutivos, de três títulos do escritor, que até então não havia tido nenhum dos seus livros traduzidos para o inglês: Epitaph of a Small Winner em 1952, Dom Casmurro em 1953 e Philosopher or Dog? em 1954.

Palavras-chave: Quincas Borba; Philosopher or Dog?; tradução; edição; circulação.

\section{CLOTILDE WILSON, CECIL HEMLEY, AND THE GENESIS OF PHILOSOPHER OR DOG? (QUINCAS BORBA)}

\begin{abstract}
This article deals with Quincas Borba's first English translation, published in 1954 under the title Philosopher or Dog?, by examining the correspondence of the translator Clotilde Wilson with the publishing house Noonday Press, especially with its editor Cecil Hemley. This material gathers unprecedented information about the professor, critic and translator, whose name is associated and somehow ended up obscured by the curious title given to the North American edition of Quincas Borba. In addition to recomposing the translation and publication process, the objective here is to place this specific translation in the context of translations of Machado de Assis's novels published in the 1950s, in order to better understand the conditions that led to the
\end{abstract}


Machado de Assis em Linha - Universidade de São Paulo http://machadodeassis.fflch.usp.br - Artigo

translations and publications in consecutive years of three titles by the writer, who until then had not had any of his books translated into English: Epitaph of a Small Winner in 1952, Dom Casmurro in 1953 and Philosopher or Dog? in 1954.

Keywords: Quincas Borba; Philosopher or Dog?; translation; edition; circulation.

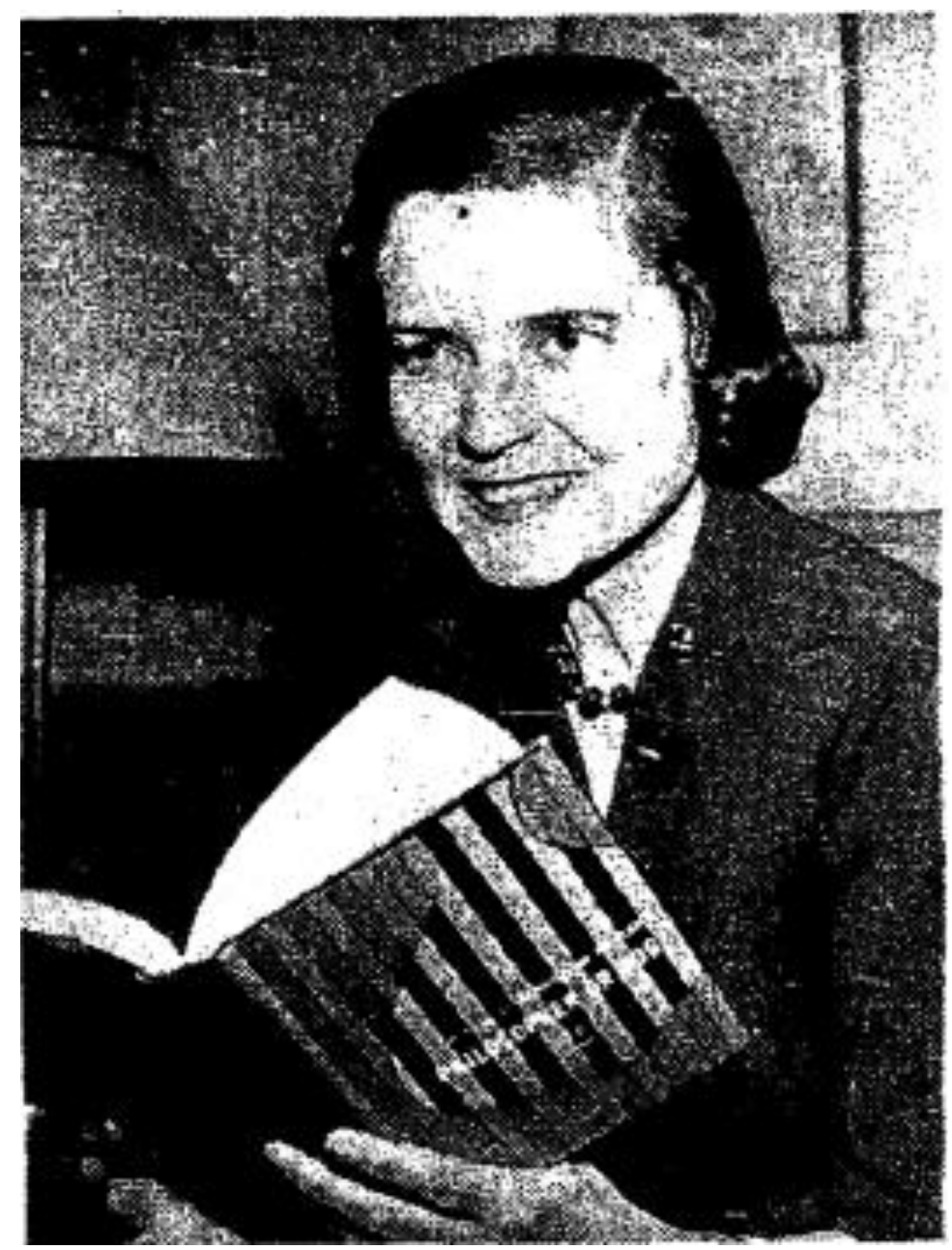

A professora, crítica e tradutora Clotilde

Marconnier Wilson, em foto para o jornal The Seattle Daily Times publicada em 3 de julho de 1955, segura um exemplar da edição de 1954 de Philosopher or Dog?, sua tradução para o inglês de Quincas Borba, de Machado de Assis, que saiu em 14 de julho de 1954 pela Noonday Press, de Nova York. 
$\mathrm{P}$ or que Machado de Assis que, mais de quatro décadas depois de sua morte, tinha apenas três contos traduzidos para o inglês, subitamente teve três dos seus principais romances traduzidos e publicados nessa língua? ${ }^{1}$ Qual seria o "sistema" por trás das três traduções geralmente tratadas como projetos avulsos, resultados do voluntarismo de três tradutores baseados em extremos geográficos dos Estados Unidos - Nova York, Los Angeles e Seattle? E por que foram publicadas por uma mesma editora, a Noonday Press, de Nova York? O que viabilizou materialmente essas traduções?

Este artigo é parte de um projeto de pesquisa que pretende responder a essas questões a partir de documentação localizada na seção de manuscritos da Biblioteca Pública de Nova York. ${ }^{2}$ Aqui, a correspondência trocada entre a tradutora de Quincas Borba para o inglês, Clotilde Wilson, e o editor Cecil Hemley, composta de 35 cartas, acrescidas de outras seis trocadas entre a tradutora e outros funcionários da editora, compõe um pequeno guia sobre o processo de tradução, edição e publicação de Philosopher or Dog? (Quincas Borba) nos Estados Unidos em 1954.

A primeira afirmação que o exame dos documentos permite fazer é que a iniciativa da Noonday Press de publicar Quincas Borba não era parte de um projeto prévio de tradução dos três romances mais consagrados de Machado de Assis. Ela decorreu da conjunção de dois fatores: por um lado, a boa repercussão da tradução das Memórias póstumas de Brás Cubas, feita por William Grossman e publicada em 1952 como Epitaph of a Small Winner pela editora nova-iorquina; ${ }^{3}$ por outro, o interesse pela literatura brasileira por

\footnotetext{
${ }^{1}$ Os contos são "O enfermeiro", "A cartomante" e "Viver!", intitulados respectivamente "The Attendant's Confession", "The Fortune-Teller", e "Life", traduzidos por Isaac Goldberg e publicados em Brazilian Tales (1921).

2 Trata-se do projeto "Machado de Assis em inglês: tradução, edição e circulação transnacional", desenvolvido com Auxílio à Pesquisa Regular Fapesp (Proc. 2020/02389-6), que permitiu o levantamento da documentação junto ao The Brooke Russell Astor Reading Room for Rare Books and Manuscripts, a seção de manuscritos e obras raras da Biblioteca Pública de Nova York, a cujos funcionários agradecemos por meio da bibliotecária Meredith Mann. A organização e a indexação dos materiais, que serviram de base para a redação deste artigo, foram feitas por Vinicius Fernandes de Oliveira no âmbito do projeto "Sobre traduções e internacionalização da obra de Machado de Assis", apoiado pelo Programa Unificado de Bolsas (PUB) da Universidade de São Paulo, no período de 1o de setembro de 2020 a 31 de agosto de 2021.

${ }^{3}$ A tradução das Memórias póstumas de Brás Cubas nos Estados Unidos foi lançada em 14 de julho de 1952 e recebeu resenhas favoráveis em alguns dos periódicos mais prestigiosos do país: o professor, tradutor e crítico americano Dudley Fitts (1952, p. 4) publicou no The New York Times um texto intitulado "A Masterpiece from Brazil"; o crítico literário inglês Anthony West (1952, p. 71) publicou na The New Yorker o texto "A Minor Classic"; e o professor de inglês da Universidade de Louisville Harvey Curtis Webster (1952, p. 9) publicou na Saturday Review um texto intitulado "A Short Life Is Not Bitter...".
} 
parte de Clotilde Wilson, professora de línguas românicas na Universidade de Washington.

A história de Philosopher or Dog? começa então em 18 de dezembro de 1952, quando Clotilde Wilson envia carta à Noonday Press, consultando a editora sobre o interesse pela tradução de Quincas Borba. A tradutora dirigese a um genérico "Gentlemen" e explica que "desde a aparição da excelente tradução de William Grossman, Epitaph of a Small Winner, por Machado de Assis, venho me perguntando se não teriam interesse na sequência do romance, Quincas Borba", segundo ela escrito com a mesma pena da galhofa e tinta da melancolia utilizadas em Brás Cubas (WILSON, 1952). ${ }^{4}$

A oportunidade surge em 1952, mas a correspondência mostra que o interesse de Clotilde Wilson por Machado de Assis data do final da década de 1940. Ele precede, portanto, a existência da editora, fundada em 1951 por Cecil Hemley e seu colega do Jewish Theological Seminary, o também escritor Arthur A. Cohen, que viria a ser a primeira difusora importante da obra de Machado de Assis nos Estados Unidos.

A ideia de traduzir o romance, segundo conta, surgiu em 1948, ao ler Marvelous Journey: A Survey of Four Centuries of Brazilian Writing. Como indica o título, o livro de Samuel Putnam (1948) apresenta um panorama entusiasmado e apaixonado da produção letrada brasileira de quatro séculos e foi publicado pela editora Knopf, desde a década de 1940 responsável pela divulgação de muitos dos autores modernos brasileiros nos Estados Unidos, entre eles Jorge Amado, Guimarães Rosa e Graciliano Ramos. O livro de Putnam teve papel importante na divulgação da literatura brasileira para o público estadunidense numa década em que o interesse pelo país crescera no contexto da Segunda Guerra Mundial e do pós-guerra. No ambiente acadêmico, isso resultou na criação de cursos de língua e literatura brasileira por todos os Estados Unidos, como ocorreu em 1943 na Universidade de Washington, onde Clotilde Wilson lecionava, e como ocorreu também na Universidade da Califórnia, Los Angeles, onde outra tradutora de Machado de Assis, Helen Caldwell, aprendeu português no início da década de 1940.

Embora tenha feito toda sua carreira acadêmica em torno principalmente da língua e da literatura francesa, ${ }^{5}$ Clotilde Wilson começou a

\footnotetext{
4 Toda a correspondência citada neste artigo, salvo indicação em contrário, encontra-se na caixa de número 219 da coleção Farrar, Straus \& Giroux, Inc. Records, sob a guarda da Biblioteca Pública de Nova York. As traduções dos documentos em inglês foram feitas pelos autores do artigo.

${ }^{5}$ Clotilde Marconnier Wilson, descendente de franceses emigrados para os Estados Unidos, nasceu e viveu em Seattle, tendo se tornado bacharel, mestra e doutora na Universidade de Washington, onde lecionou por 47 anos, de 1929 a 1976, ano em que se aposentou como Professor Emeritus of French Language and Literature. Em 1927, tornou-se mestre com a dissertação The Theme of Sophonisba as
} 
ministrar disciplinas de literatura brasileira em $1944 .{ }^{6} \mathrm{Em} \mathrm{1948,} \mathrm{ela} \mathrm{consta}$ como a única professora de "Braz. Lit.", ou seja, literatura brasileira, da Universidade de Washington ${ }^{7}$ e, em 1950, aparece como supervisora de quatro alunos no estudo de português. ${ }^{8}$

A leitura do livro de Samuel Putnam provavelmente está associada às suas atividades como professora de literatura brasileira e nele uma afirmação chamou especialmente sua atenção: a do grande atraso em se traduzir para o inglês "o maior romancista latino-americano".?

Clotilde Wilson tomou a tarefa para si e pôs-se a buscar editores para a sua tradução de Quincas Borba, sem sucesso. Ao responder ao aceno positivo da Noonday Press, Wilson escreveu em 9 de janeiro de 1953 uma carta, desta vez endereçada a Cecil Hemley, na qual informava já ter traduzido um terço do livro e fazia o seguinte comentário: "Bem, eu apenas não havia escrito para as pessoas certas, não é?" (WILSON, 1953a).

As cartas não permitem precisar exatamente quando Wilson começou a traduzir o romance, mas o primeiro registro público do seu interesse por Machado de Assis e, mais especificamente, por Quincas Borba, data de maio de 1949, quando publicou na revista Hispania o artigo "Machado de Assis, Encomiast of Lunacy". Nele, cita trechos do romance traduzidos para o inglês, compara as teses do psicólogo George Estabrooks e a do teólogo e filósofo humanista Erasmo de Roterdã sobre a loucura, associando-as a personagens machadianas, tais como Brás Cubas, Quincas Borba e Rubião.

Para Wilson (1949), a presença frequente do tema da loucura nos escritos de Machado de Assis seria mais uma manifestação do pessimismo machadiano, uma visão muito disseminada entre leitores à época, tanto no Brasil como nos Estados Unidos. Uma vez que para o escritor a vida seria marcada pelo desencanto e por uma tristeza insuportável, apenas por meio da loucura seria possível atingir a ilusão de felicidade, que é o que ocorre com Rubião e outros personagens megalômanos da galeria machadiana.

Treated by Corneille and Voltaire and their Romantic Predecessors e, em 1931, doutorou-se com a tese Proust and Stendhal: A Study in Analogies.

6 A informação consta dos General Catalogs da Universidade de Washington, disponíveis em $<$ https://www.washington.edu/students/gencat/archive/>. Os autores agradecem ao Professor Eduardo Viana da Silva, coordenador do programa de português da Universidade de Washington, e a Deb Raftus, bibliotecária para os programas de estudos do francês e italiano, espanhol e português, América Latina e Caribe na mesma universidade, pelo apoio para obtenção de informações sobre a trajetória acadêmica de Clotilde Wilson.

${ }^{7}$ Cf. Pan American Union (1948).

${ }^{8}$ Cf. International Colloquium on Luso-Brazilian Studies (1953, p. 335).

${ }^{9}$ Wilson detalha esse assunto na enquete que respondeu para a Noonday Press (1954), com subsídios para a divulgação da tradução de Quincas Borba. O documento manuscrito está na pasta "Machado de Assis General Epitaph of a Small Winner 1953-4". 
Clotilde Wilson ressalta no artigo seu interesse pela dimensão abstrata e filosófica do romance, principalmente no que diz respeito à loucura, aos limites e às sobreposições entre razão e loucura, que considera os temas machadianos por excelência. Assim como seus colegas tradutores de Machado de Assis para o inglês, enfatizava o alcance universal das questões machadianas, talvez por serem mais palpáveis para o leitorado norteamericano, em geral pouco ou nada familiarizado com o Brasil e as questões brasileiras.

A visão do romance expressa no artigo de 1949 se faz presente também no breve "Prefácio da tradutora", que acompanha a tradução de 1954 (WILSON, 1954c). Ali, em pouco mais de três páginas, retoma as principais ideias e recupera várias passagens do artigo, acrescentando de mais significativo apenas a sugestão de comparação do romance com o poema "A mosca azul", publicado pela primeira vez na Revista Brasileira, em 1880, e posteriormente recolhido por Machado de Assis nas suas Poesias completas (1901). Curiosamente, a tradutora não discute em seu prefácio nenhuma questão ou dificuldade da tradução. É como se no intervalo que separa o artigo de 1949 e a publicação da tradução em 1954 nada tivesse a acrescentar à sua visão do romance por meio do embate com o texto, que o trabalho de tradução supõe. Entretanto, não será bem assim, pois, como se verá adiante, Wilson se mostra atenta e muito aflita com o acabamento do texto em vias de publicação.

Entre a primeira carta dela para Hemley e o envio da primeira versão da tradução decorreram pouco mais de dois meses, o que sugere que a tradução de fato estava muito adiantada quando fez o primeiro contato com a editora. Em 27 de fevereiro de 1953, ela encaminhou à Noonday o restante da tradução do livro. Em 17 de março, Cecil Hemley envia seu parecer, dizendo que com um pouco mais de trabalho a tradução "estará perfeitamente publicável" (HEMLEY, C., 1953b). Entretanto, o editor aponta um obstáculo para a publicação: a W. M. Jackson, Inc., que então detinha os direitos autorais sobre a obra de Machado de Assis, havia cedido os direitos sobre a tradução para o inglês de Quincas Borba a François Ivanhoe, professor do Reed College, faculdade de artes liberais localizada em Portland, Oregon. Para Hemley, antes de avançar no projeto, era preciso resolver essa questão, para evitar problemas com os direitos e o risco de um litígio.

Hemley entra então em contato com o professor, informando que já publicara a tradução das Memórias póstumas, a de Dom Casmurro estava a caminho, e que gostaria de ter um terceiro romance, Quincas Borba, também no catálogo da Noonday Press. O editor pergunta, então, se Ivanhoe já havia 
avançado na tradução (HEMLEY, C., 1953a). A resposta é um tanto ácida. Ivanhoe diz que de fato a W. M. Jackson lhe concedeu, sem que pedisse, a autorização para publicar Quincas Borba, mas que ele não levaria a cabo a tarefa:

Em primeiro lugar, eu nunca tive interesse particular pelo livro: do ponto de vista do tradutor, trata-se de um genuíno abacaxi; do ponto de vista literário, ele não chega nem perto de Brás Cubas. [...] o livro é difícil; não tem o apelo e nem as virtudes de Brás Cubas; na minha opinião virá mais como um anticlímax depois das Memórias. Não gostaria de examinar novamente o Quincas Borba e me explicar o motivo do seu otimismo? Eu ficaria muito feliz de estar errado. (IVANHOE, 1953)

A correspondência entre Ivanhoe e Hemley aparentemente parou por aí, e o editor não mudou sua opinião. Em 26 de junho, Clotilde Wilson concordou com os termos propostos, ${ }^{10}$ e o contrato começou a ser preparado (WILSON, 1953c).

\section{Dilemas da tradução}

Resolvidas as questões burocráticas, Wilson e Hemley voltam-se para as questões textuais da tradução.

O título é a questão mais sensível, e a discussão sobre ele se estende por várias cartas trocadas no mês de dezembro de 1953. Em 10 de dezembro, o editor Cecil Hemley dá início à discussão. Evocando razões comerciais, pondera que o nome em português traz uma sequência de sílabas e sons completamente desconhecidos para o leitor anglófono, daí sugerir que o nome venha acompanhado do subtítulo "Man or Dog?".

Hemley diz que o assunto do título já havia sido bastante debatido na editora e que a solução do subtítulo vinha da tradução do romance para o italiano, Gioachin Borba, L'uomo o il cane?, feita por Giuseppe Alpi e publicada em Milão em 1930. Informa também que submetera o título a William Grossman, o tradutor de Brás Cubas, contando com sua aprovação. O subtítulo interrogativo, para Hemley, não distorcia o título dado por Machado e poderia

\footnotetext{
${ }^{10}$ A W. M. Jackson exigia 5\% de royalties sobre o preço de capa do livro. Hemley oferece a Wilson os mesmos $5 \%$ de royalties sobre o preço de capa, informando que era a mesma percentagem paga a Helen Caldwell, tradutora de Dom Casmurro, com a diferença de que, no caso de Caldwell, ela mesma ficou responsável pelos acertos com a Jackson. A Noonday pagou ainda um adiantamento de US\$250 dos royalties, e Wilson teria direito sobre um quarto das vendas ou qualquer reimpressão feita pelo Book Club (HEMLEY, C., 1953c).
} 
impulsionar a venda da tradução. O editor faz essas considerações ao mesmo tempo em que informa à tradutora sobre a dificuldade que enfrenta para emplacar os livros de Machado de Assis nos Estados Unidos, referindo-se às vendas de Epitaph of a Small Winner, lançado no ano anterior (HEMLEY, C., 1953d).

A resposta de Clotilde Wilson, de 15 de dezembro de 1953, põe fortes objeções ao subtítulo Man or Dog?, informando que essa foi também a reação instantânea e unânime dos colegas da universidade a quem apresentou a solução. Para a tradutora, a alternativa entre homem e cão sugeria algo como um freak show de segunda categoria, uma aberração biológica. Na enquete enviada pela Noonday Press à tradutora, respondida por esses mesmos dias, Wilson rejeitava a proposta de Hemley com o mesmo argumento da aberração e aventava duas possibilidades: Quincas Borba, Victor or Vanquished?, algo como "Quincas Borba, vitorioso ou vencido?", que considerava um pouco pesado ("ponderous"), e Quincas Borba, To the Victor, the Potatoes, ao qual não punha nenhuma objeção (NOONDAY PRESS, 1954).

Wilson propõe então que o subtítulo remeta à dimensão mais filosófica do romance, fazendo referência ao capítulo 6, em que Quincas Borba explica o sentido da vida e da morte de acordo com a doutrina de Humanitas, para a qual rigorosamente não há morte: "Hás de lembrar-te que as bolhas fazem-se e desfazem-se de contínuo, e tudo fica na mesma água. Os indivíduos são essas bolhas transitórias" (ASSIS, 1977, p. 114). A partir desse trecho, a tradutora propõe os subtítulos "Bubble of Eternity" ou "Bubble of Immortality", bolha da eternidade ou bolha da imortalidade, utilizando um oximoro que de alguma forma enfatizasse as contradições e os absurdos apresentados pelo romance.

Para defender sua proposta, Wilson supõe que a escolha do nome da personagem, Borba, esteja motivada pela semelhança sonora com borbotar e borbulhar, retomando a célebre pergunta shakespeariana sobre "o que há num nome":

Que tal Quincas Borba, Bubble of Eternity (ou of Immortality), ou Quincas Borba, Little Bubble (ou Poor Bubble) of Eternity? Bem, acho que não vão servir. Mas, por favor, vamos pensar no assunto um pouco mais, se ainda houver tempo. Suspeito que, se tiverem outra conversa sobre o título, você citará "Bubble, bubble, toil and trouble" [Bolhas, bolhas, males e aflição $]^{11}$ e acrescentará "Que velha bruxa a Clotilde deve ser!". (WILSON, 1953e)

\footnotetext{
${ }^{11}$ A referência aqui é à Cena 1 do Ato 4 de Macbeth, em que as bruxas, mexendo o caldeirão, dizem em
} uníssono: "Double, Double toil and trouble; / Fireburn, and cauldron bubble". Os versos foram 
Na resposta de 17 de dezembro de 1953, Cecil Hemley sequer considera essas possibilidades, oferecendo três alternativas para o subtítulo: "Master or Dog", "Philosopher or Dog", e "Man or Dog". É a primeira vez que aparece a forma que finalmente será a adotada como título (HEMLEY, C., 1953e), acompanhado na página de rosto por Quincas Borba, entre parênteses.

A resposta de Clotilde Wilson, de 23 de dezembro, é bastante sucinta, desta vez sem qualquer elucubração. A concordância com as alternativas que lhe foram apresentadas e a preferência por "Philosopher or Dog" vêm pontuadas pelas palavras "creio" e "talvez", sugerindo certa hesitação e contrariedade, ainda que o título contemplasse o aspecto filosófico que a tradutora enfatizava no romance: "dos títulos que você sugere para Quincas Borba, creio gostar mais do último, Philosopher or Dog, embora, talvez, como você diz, qualquer um deles servisse" (WILSON, 1953f).

Wilson não parece ter grandes hesitações em pontos geralmente desafiadores para os tradutores de Machado de Assis, como a tradução de termos ligados à escravidão (moleque, pajem, preto, preta, escravaria) e à cor da pele (cor fula). "Pajem" será traduzido por "houseboy", "moleque" por "Negro boy", "preto", como substantivo, virá como "Negro", e preta como "Negress". "Cor fula" (que originariamente se refere à cor dos que pertencem ao grupo dos fulas, "de cor parda, tendendo ao marrom ou ao amarelado" e, por extensão, referindo-se ao que muda de cor, tornando-se geralmente pálido, termo que se mantém vivo na expressão "ficar fulo da vida", no sentido de ficar irado, bravo, mudando de cor ou empalidecendo por irritação) será traduzido com simplicidade por "light-colored".

Entretanto, um outro problema de tradução surge nas cartas de 26 de janeiro e 3 de fevereiro de 1954, nas quais Wilson (1954a) e Hemley (1954a) discutem o uso dos termos "fellow-godmother" e "fellow-godfather" para "comadre" e "compadre". Se os termos no Brasil podem ser usados informalmente entre amigos muito próximos, para um leitor americano os termos em inglês podem soar confusos, ainda mais quando aparecem na expressão "sinhá comadre". Afinal, a solução adotada por Wilson é "friend", "good friend" ou simplesmente a supressão do termo, referindo-se à personagem diretamente pelo seu nome próprio, Angélica ou Rubião, descartando o qualificativo.

traduzidos por Bárbara Heliodora como "Dobrem males e aflição / Nas bolhas do caldeirão". Cf. Shakespeare (2016, p. 716). 
Wilson hesita ainda em relação a um diálogo do capítulo 17, em que o personagem Rubião diz para a comadre Angélica duas vezes "prometo-lhe um filho" (ASSIS, 1977, p. 125). Wilson não sabe se esse filho se referia a um futuro filho de Rubião ou a um filhote do cachorro, já que no português é comum o uso da palavra "filho" para se referir também à prole de um animal, ao passo que no inglês o mais comum é usar a palavra "son" para "filho" e "pup" para o filhote de um animal. Ainda que em português a promessa de Rubião seja mesmo ambígua, e talvez abusada, no livro em inglês prevaleceu a acepção canina, "pup".

Já na fase das provas, iniciada em março de 1954, Wilson solicita várias emendas, relativas especialmente ao uso das aspas e da pontuação. Entre 31 de março e $1^{\underline{0}}$ de abril, Cecil Hemley e sua esposa, Elaine Gottlieb Hemley, que trabalhava como revisora da Noonday Press, escrevem para Wilson dizendo que a maior parte das alterações que ela deseja fazer são desnecessárias e informam que a editora, por contrato, se responsabiliza apenas por alterações que acarretem custo de até cem dólares e que qualquer coisa para além disso correrá por conta da tradutora (HEMLEY, C., 1954b; HEMLEY, E. G., 1954). Ainda assim, Wilson insiste que mais uma revisão seja feita; ela diz em 2 de abril que as aspas não são um problema, mas que as vírgulas são, e diz estar disposta a pagar cem dólares do seu adiantamento, ou mesmo cento e cinquenta dólares, para que a revisão seja feita integralmente (WILSON, 1954b).

A correspondência, bastante tensa nesse momento, indica tanto o cuidado com o acabamento do texto como a falta de prática de Wilson no trato com editoras. De fato, ela era uma figura relativamente estranha ao meio editorial. Até aquele momento, publicara apenas um livro, a tradução do espanhol de Las Memorias de Mamá Blanca (1932) em colaboração com Carlos García-Prada, professor de espanhol na Universidade de Washington. Como se viu, sua aproximação a Cecil Hemley se deu por meio de correspondência bastante impessoal com a Noonday Press. Wilson também não tinha relações prévias com os outros dois tradutores de Machado de Assis, William Grossman e Helen Caldwell. Entretanto, a correspondência mostra suas conexões com alguns agentes importantes para a difusão da cultura brasileira nos Estados Unidos. Entre eles, Erico Verissimo, então baseado em Washington, D.C. como diretor do Departamento de Assuntos Culturais da Pan American Union. Wilson também conhecia Edmundo da Silveira, funcionário do Departamento de Estado dos Estados Unidos, que tinha lhe ajudado a dirimir dúvidas sobre o uso de alguns termos em português. 


\section{A carreira da tradutora}

Ao contrário de William Grossman e Helen Caldwell, para quem as traduções das Memórias póstumas e de Dom Casmurro marcaram o início de uma "carreira" paralela como tradutores, a atividade de Wilson como tradutora foi bastante restrita, resumindo-se a apenas mais dois títulos.

Concomitantemente ao processo de edição de Philosopher or Dog?, e a partir de outubro de 1953, Wilson passou a se dedicar à tradução do romance Lições de abismo, de Gustavo Corção, cuja leitura lhe havia sido indicada por Erico Verissimo. Apesar do empenho e de certa insistência dela em tentar viabilizar a publicação do livro pela Noonday, Cecil Hemley é evasivo ao cogitar a edição de outro escritor brasileiro: "[...] não coloque muita esperança em Corção; temos dificuldade para vender o Machado, e um escritor brasileiro de menor expressão será extremamente difícil de lançar nos dias de hoje" (HEMLEY, C., 1953d).

A desistência definitiva de Hemley deveu-se ao que ele considerava o baixo potencial comercial de autores de língua portuguesa nos Estados Unidos, haja vista que mesmo Machado de Assis e Eça de Queirós, considerados grandes nomes da literatura dessa língua, enfrentavam dificuldade para serem vendidos, apesar de receberem resenhas elogiosas (HEMLEY, C., 1954c).

Apesar da negativa da Noonday, Clotilde Wilson levou a cabo a tradução de Lições de abismo ainda em 1954, mas Who If I Cry Out, título da versão em inglês, só viria a ser publicado em 1967 pela University of Texas Press. De Corção, ela traduziu também $A$ descoberta do outro, publicado em 1957 na Inglaterra pela Longmans, Green \& Co. como My Neighbour as Myself.

$\mathrm{O}$ interesse de Wilson pela obra de Corção reforça seu interesse pela literatura de fundo filosófico, que foi, como vimos, o traço que mais a atraiu nos escritos de Machado de Assis e que fez com que ela em vários momentos associasse os dois autores (WILSON, 1953d).

\section{A carreira do livro}

A repercussão de Philosopher or Dog? na imprensa norte-americana foi bastante mais modesta do que a registrada por Epitaph of a Small Winner e Dom Casmurro. A resenha mais substancial saiu em 17 de julho de 1954 e intitulava-se "Victory and Potatoes". Assinado por William Grossman, que 
muito provavelmente o escreveu a pedido da editora, o texto destacava o início da formação de um séquito de admiradores de Machado de Assis também no Estados Unidos, devido às recentes traduções de seus romances, chamava a atenção para a ironia do título em inglês e terminava dizendo que, apesar de todos os seus méritos, Philosopher or Dog? dificilmente entraria na lista dos best-sellers. Para Grossman (1954), a cena em que Sofia conta ao marido sobre as investidas sexuais de Rubião é um dos episódios mais reveladores e incômodos sobre os arranjos conjugais, e era difícil esperar que o leitor médio, uma vez compreendida a ironia do livro, suportaria ser criticado em uma questão tão sensível como sua intimidade familiar e conjugal.

Em 1955, Philosopher or Dog? faz uma aparição na lista de livros de autores negros na revista Phylon. ${ }^{12}$ Como hoje se sabe, já desde a década de 1930 Machado de Assis constava em catálogos bibliográficos norteamericanos como "black author" ou "negro author", conforme documentação encontrada no Schomburg Center for Research in Black Culture. ${ }^{13}$

Entre os romances de Machado de Assis traduzidos para o inglês e publicados na década de 1950, Quincas Borba foi também o que teve menor circulação. Epitaph of a Small Winner teve várias reimpressões entre 1952 e 1964, totalizando 24.040 exemplares..$^{14}$ Dom Casmurro também teve algumas reimpressões entre 1953 e 1961, somando 11 mil exemplares. ${ }^{15}$ Não há informações sobre a tiragem da primeira edição de Philosopher or Dog?, mas tudo indica que tenha sido de algo em torno de 5 mil, acompanhando as tiragens iniciais dos títulos anteriores. De qualquer modo, é certo que a tradução de Clotilde Wilson teve apenas uma impressão pela Noonday Press em 1954 e no mesmo ano saiu em edição inglesa pela W. H. Allen, com o título modificado para The Heritage of Quincas Borba, com tiragem de 3.294 exemplares (POLLINGER, 1961).

\footnotetext{
12 Cf. Jackson (1955).

${ }^{13}$ Sobre o assunto, cf. Guimarães (2017, p. 11-28).

${ }^{14}$ As informações sobre as reimpressões de Epitaph of a Small Winner entre 1952 e 1964 constam dos seguintes documentos: carta de Herman Figatner, da controladoria do Book Find Club, para Arthur A. Cohen, 11 nov. 1954; carta de Gerald J. Pollinger, agente literário da Laurence Pollinger Ltd., para Fred Warburg, da editora Secker \& Warburg, 22 nov. 1961; carta de Barbara Holler, assistente da Noonday Press, para Luiz Fernando Nazareth, Oficial de Assuntos Culturais da Embaixada Brasileira em Washington, 2 mar. 1964. O primeiro documento está na pasta "Machado de Assis General Epitaph of a Small Winner 1953-4"; os outros dois, na pasta "General Correspondence 1960-5"; todos os três na caixa 218 da Coleção Farrar, Straus \& Giroux, Inc. Record Box 218.

${ }^{15}$ As reimpressões de Dom Casmurro entre 1953 e 1961 estão listadas em: carta de Arthur A. Cohen para Mário Guimarães, 13 jan. 1953; carta de Barbara Holler mencionada na nota anterior. A primeira consta da pasta "Machado de Assis General Dom Casmurro 1952-3", na caixa 218 da Coleção Farrar, Straus \& Giroux, Inc. Record Box 218.
} 
Lançada a tradução, a correspondência de Wilson Clotilde com a Noonday Press cessa por vários anos.

Em outubro de 1960, Wilson pergunta a Robert Wohlforth, tesoureiro da Farrar, Straus \& Cudahy, que acabara de adquirir a Noonday Press, por que o livro não constava do catálogo da editora. Elizabeth Pollet, editora assistente, em $1^{\underline{o}}$ de novembro respondeu-lhe que o livro estava esgotado, sem mencionar qualquer plano de reimpressão ou nova edição.

À carta de 1960, segue-se outro longo período de silêncio, quebrado apenas em 1982, quando Wilson, já aposentada da universidade, escreve para Elizabeth Besobrasow, do Departamento de Contrato e Direitos Autorais da agora Farrar, Straus \& Giroux, autorizando a renovação dos direitos de Philosopher or Dog?. Justamente em 1982, a tradução sai em edição de bolso da Bard Book/Avon Books, de Nova York, em acordo com a Farrar, Straus \& Giroux, que quatro anos antes havia publicado na mesma série, intitulada "Distinguished Latin American Fiction", Epitaph of a Small Winner, Dom Casmurro e obras de vários outros autores latino-americanos, incluindo os brasileiros Jorge Amado e Rachel de Queiroz.

Em 1992, saiu uma reimpressão da tradução pela Farrar, Straus \& Giroux, com capa modificada. Em 1997, a editora londrina Bloomsbury, que se tornou mundialmente conhecida com a publicação da série Harry Potter, lançou uma edição inglesa com a tradução de Clotilde Wilson. Essa edição ainda consta do catálogo da Bloomsbury e está disponível para venda no site da editora, o que sugere que ainda não tenha se esgotado.

Em 1998, a Oxford University Press publicou uma nova tradução do romance mantendo o título em português, Quincas Borba, seguido do subtítulo A Novel by Machado de Assis. A segunda tradução do romance é assinada por Gregory Rabassa, que desde a década de 1960 se tornara uma estrela entre os tradutores de autores latino-americanos, com o enorme sucesso de sua tradução de Cem anos de solidão, de Gabriel García Márquez. Desde então, não há registro de novas edições ou reimpressões de Philosopher or Dog?.

Ao ser perguntada pela Noonday Press sobre os principais eventos de sua vida (atividades, viagens, projetos, hobbies), para fins de divulgação de Philosopher or Dog?, Clotilde Wilson deu uma resposta comovente:

Temo não poder ser muito útil. Quando que os 'eventos' da minha vida foram muito importantes? Tenho certeza de que eles importariam muito pouco para qualquer outra pessoa. Mesmo minhas viagens (viajei muito pelos Estados Unidos, Canadá, Europa e México) não são do tipo que 
merecem divulgação, já que não tiveram nada de excepcional. (NOONDAY PRESS, 1954)

Não há registro de que tenha visitado o Brasil. Traduziu o mais longo romance de Machado de Assis muito provavelmente a partir do aprendizado da língua portuguesa na Universidade de Washington e de leituras feitas por conta própria. Tudo indica que a tradução e publicação de Quincas Borba tenha sido um dos grandes eventos de sua vida, por envolver obra, autor e língua que não faziam parte da sua formação principal, e também por ser nos exemplares de Philosopher or Dog? que seu nome circulou mais amplamente e ainda, de alguma forma, sobrevive.

Clotilde Wilson morreu em 18 de janeiro de 1997, em Seattle, aos noventa anos. 


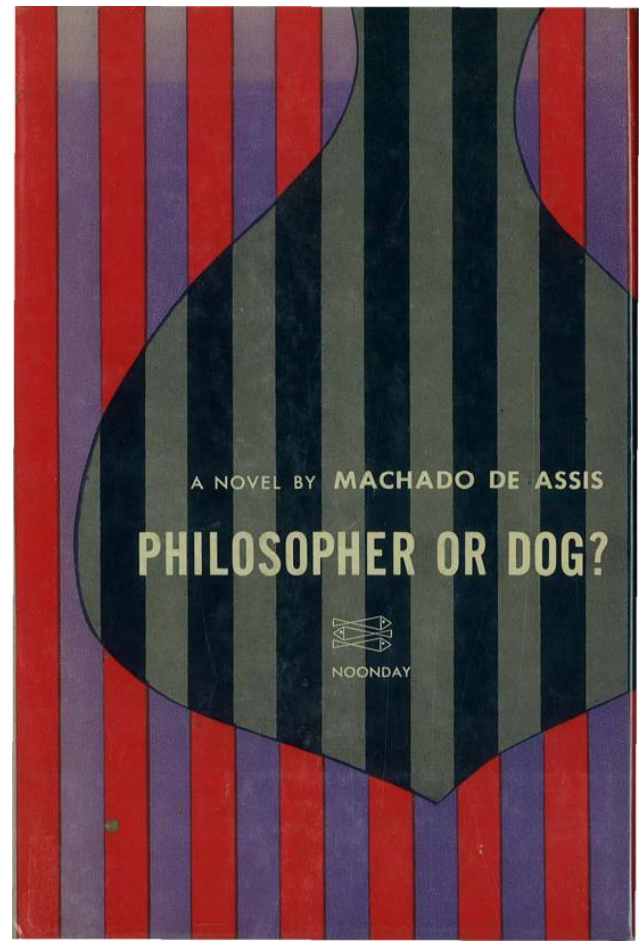

Capa da primeira edição publicada em 1954 pela Noonday Press.

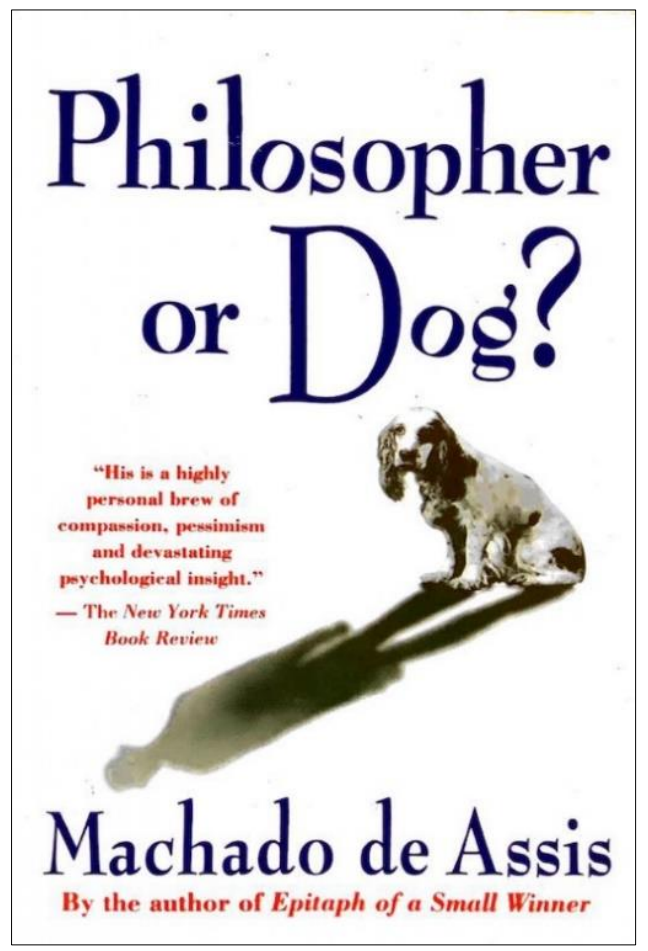

Capa da edição publicada em 1992 pela Farrar, Straus and Giroux.

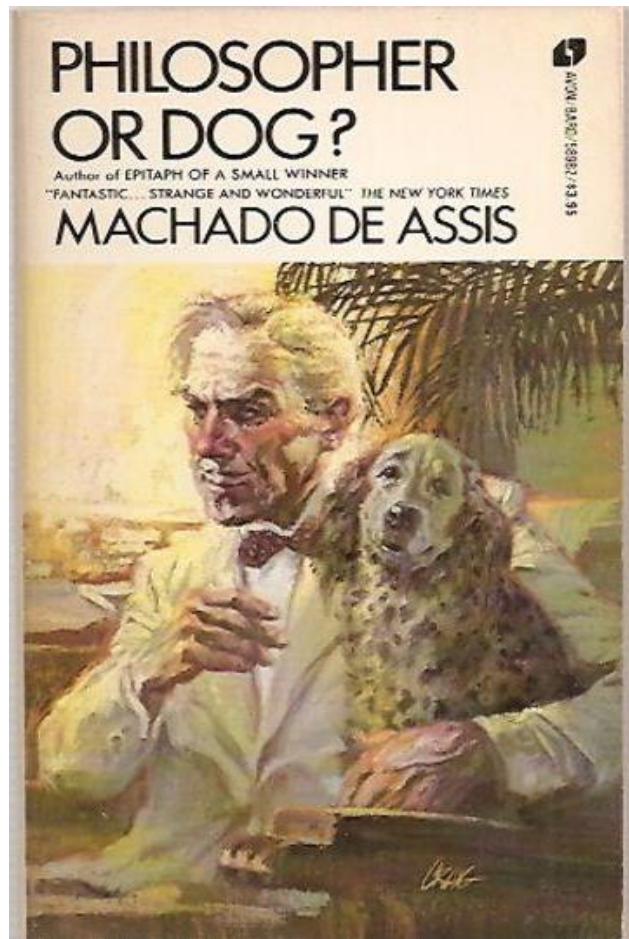

Capa da edição de 1982 publicada pela Avon Bard em formato de livro de bolso.

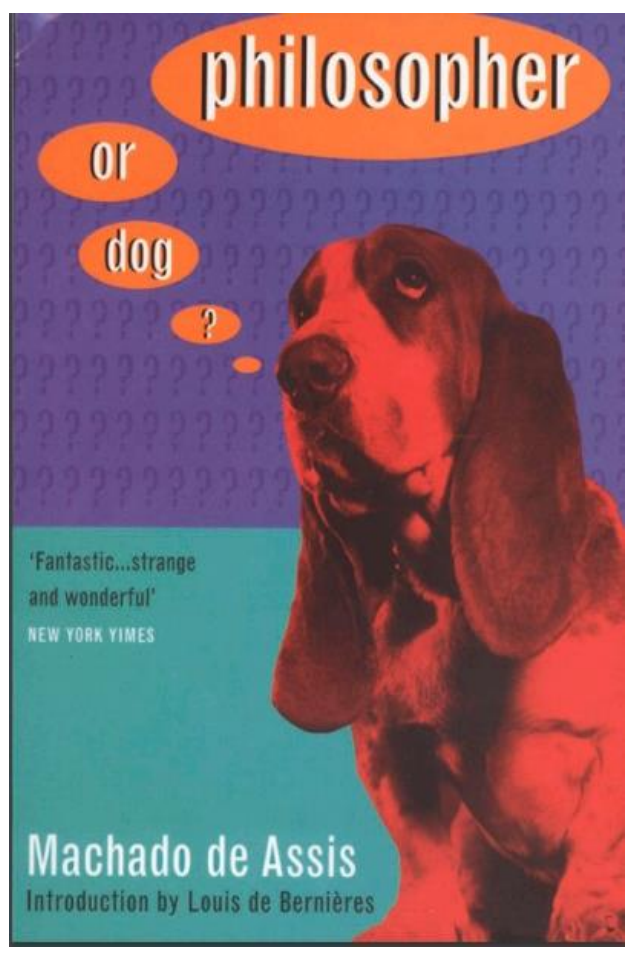

Capa da edição publicada em 1997 pela Bloomsbury Publishing. 


\section{Referências}

ASSIS, Machado de. Quincas Borba. 2. ed. Rio de Janeiro: Civilização Brasileira; Brasília: INL, 1977. p. 114, p. 125.

; GROSSMAN, William L. Epitaph of a Small Winner. Tradução de William L. Grossman e ilustrações de Shari Frisch. Nova York: Noonday Press, 1952.

; CALDWELL, Helen. Dom Casmurro. Tradução de Helen Caldwell e introdução de Waldo Frank. Nova York: Noonday Press, 1953.

; WILSON, Clotilde. Philosopher or Dog?. Tradução de Clotilde Wilson. Nova

York: Noonday Press, 1954a.

; WILSON, Clotilde. The Heritage of Quincas Borba. Tradução de Clotilde Wilson. Londres: W. H. Allen, 1954b.

COHEN, Arthur A. [Carta de 13 de janeiro de 1953]. Destinatário: Mário Guimarães. Nova York, 1953. 1 carta pessoal. Cópia datiloscrita. Caixa 218 da Coleção Farrar, Straus \& Giroux, Inc. Pasta "Machado de Assis General Dom Casmurro 1952-3".

CORÇÃO, Gustavo; WILSON, Clotilde. My Neighbour as Myself. Tradução de Clotilde Wilson. [Londres]: Longmans, Green \& Co., 1957.

; WILSON, Clotilde. Who If I Cry Out. Tradução de Clotilde Wilson. [Austin, Texas, EUA]: University of Texas Press, 1967.

FIGATNER, Herman. [Carta de 11 de novembro de 1954]. Destinatário: Arthur A. Cohen. Nova York, 1954. 1 carta pessoal. Cópia datiloscrita. Caixa 218 da Coleção Farrar, Straus \& Giroux, Inc. Pasta "Machado de Assis General Epitaph of a Small Winner 1953-4".

FITTS, Dudley. A Masterpiece from Brazil, The New York Times, Nova York, 13 jul. 1952, p. 4.

GOLDBERG, Isaac (Org.). Brazilian Tales. Tradução e introdução de Isaac Goldberg. Boston, Massachusetts, EUA: The Four Seas Company, 1921.

GROSSMAN, William. Victory and Potatoes. Saturday Review 37, [s. l.], p. 12, 17 jul. 1954. Disponível em: <https://www.unz.com/print/SaturdayRev-1954jull700012/>. Acesso em: 13 out. 2021.

GUIMARÃES, Hélio de Seixas. Race and Color in the Reception of Machado de Assis. Luso-Brazilian Review, Madison, v. 54 n. 2, p. 11-28, 2017. Disponível em: $<$ muse.jhu.edu/article/683448>. Acesso em: 13 out. 2021.

HEMLEY, Cecil. [Carta de 8 de março de 1953]. Destinatário: François Ivanhoe. Nova York, 1953a. 1 carta pessoal. Cópia datiloscrita. Caixa 219 da Coleção Farrar, Straus \& Giroux, Inc. Pasta "Machado de Assis General Epitaph of a Small Winner 1953-4". . [Carta de 17 de março de 1953]. Destinatário: Clotilde Wilson. Nova York, 1953b. 1 carta pessoal. Cópia datiloscrita. Caixa 219 da Coleção Farrar, Straus \& Giroux, Inc. Pasta "Machado de Assis General Epitaph of a Small Winner 1953-4".

. [Carta de 23 de junho de 1953]. Destinatário: Clotilde Wilson. Nova York, 1953c.

1 carta pessoal. Cópia datiloscrita. Caixa 219 da Coleção Farrar, Straus \& Giroux, Inc. Pasta "Machado de Assis General Epitaph of a Small Winner 1953-4". 
. [Carta de 10 de dezembro de 1953]. Destinatário: Clotilde Wilson. Nova York, 1953d. 1 carta pessoal. Cópia datiloscrita. Caixa 219 da Coleção Farrar, Straus \& Giroux, Inc. Pasta "Machado de Assis General Epitaph of a Small Winner 1953-4". . [Carta de 17 de dezembro de 1953]. Destinatário: Clotilde Wilson. Nova York, 1953e. 1 carta pessoal. Cópia manuscrita. Caixa 219 da Coleção Farrar, Straus \& Giroux, Inc. Pasta "Machado de Assis General Epitaph of a Small Winner 1953-4". . [Carta de 26 de janeiro de 1954]. Destinatário: Clotilde Wilson. Nova York, 1954a. 1 carta pessoal. Cópia datiloscrita. Caixa 219 da Coleção Farrar, Straus \& Giroux, Inc. Pasta "Machado de Assis General Epitaph of a Small Winner 1953-4". [Carta de 31 de março de 1954]. Destinatário: Clotilde Wilson. Nova York, 1954b. 1 carta pessoal. Cópia datiloscrita. Caixa 219 da Coleção Farrar, Straus \& Giroux, Inc. Pasta "Machado de Assis General Epitaph of a Small Winner 1953-4". . [Carta de 9 de setembro de 1954]. Destinatário: Clotilde Wilson. Nova York, 1954c. 1 carta pessoal. Cópia manuscrita. Caixa 219 da Coleção Farrar, Straus \& Giroux, Inc. Pasta "Machado de Assis General Epitaph of a Small Winner 1953-4". HEMLEY, Elaine Gottlieb. [Carta de $1^{\varrho}$ de abril de 1954]. Destinatário: Clotilde Wilson. Nova York, 1954. 1 carta pessoal. Cópia datiloscrita. Caixa 219 da Coleção Farrar, Straus \& Giroux, Inc. Pasta "Machado de Assis General Epitaph of a Small Winner 1953-4".

HOLLER, Barbara. [Carta de 2 de março de 1964]. Destinatário: Luiz Fernando Nazareth. Nova York, 1964. 1 carta pessoal. Cópia datiloscrita. Caixa 218 da Coleção Farrar, Straus \& Giroux, Inc. Pasta "General Correspondence 1960-5".

INTERNATIONAL COLLOQUIUM ON LUSO-BRAZILIAN STUDIES, 1950, Washington. Proceedings [...]. Nashville: The Vanderbilt University Press, 1953.

IVANHOE, François. [Carta de 12 de março de 1953]. Destinatário: Cecil Hemley. Nova York, 1953. 1 carta pessoal. Cópia datiloscrita. Pasta "Machado de Assis General Epitaph of a Small Winner 1953-4".

JACKSON, Blyden. The Blithe Newcomers, Resume of Negro Literature in 1954: Part I. Phylon (1940-1956), Atlanta, v. 16, n. 1, p. 5-12, 1955. Disponível em: <www.jstor.org/stable/272612>. Acesso em: 10 mar. 2021. doi: 10.2307/272612.

NOONDAY PRESS. [Enquete de divulgação da Noonday Press]. Destinatário: Clotilde Wilson. Nova York, 1954. 1 enquete. Manuscrito preenchido por Clotilde Wilson. Caixa 219 da Coleção Farrar, Straus \& Giroux, Inc. Pasta "Machado de Assis General Epitaph of a Small Winner 1953-4".

PAN AMERICAN UNION. Division of Intellectual Cooperation. Latin American Studies: A List of Persons Conducting Courses Dealing with Latin America in American Colleges and Universities. Washington, D.C.: Pan American Union, 1948.

PARRA, Teresa de La; GARCÍA-PRADA, Carlos; WILSON, Clotilde. Las Memorias de Mamá Blanca: Edited with introduction, notes, exercises and vocabulary. Tradução de Carlos García-Prada e Clotilde Wilson. Nova York: Macmillan, 1932. 
POLLET, Elizabeth. [Carta de $1^{\circ}$ de novembro de 1960]. Destinatário: Clotilde Wilson. Nova York, 1960. 1 carta pessoal. Caixa 600 MssCol979 da Coleção Farrar, Straus \& Giroux, Inc. Pasta "de Assis, M. All Corr. Philosopher or Dog".

POLLINGER, Gerald J. [Carta de 22 de novembro de 1961]. Destinatário: Fred Warburg. Nova York, 1961. 1 carta pessoal. Cópia datiloscrita. Caixa 218 da Coleção Farrar, Straus \& Giroux, Inc. Pasta "General Correspondence 1960-5".

PUTNAM, Samuel. Marvelous Journey: A Survey of Four Centuries of Brazilian Writing. Nova York: Alfred A. Knopf, 1948.

SHAKESPEARE, William. Tragédias e comédias sombrias. Tradução de Bárbara Heliodora. São Paulo: Nova Aguilar, 2016. p. 716.

WEBSTER, Harvey Curtis. A Short Life Is Not Bitter... Saturday Review 35, [s. l.], p. 9, 26 jul. 1952.

WEST, Anthony. A Minor Classic. The New Yorker, Nova York, p. 71, 9 ago. 1952.

WILSON, Clotilde. Machado de Assis, Encomiast of Lunacy. Hispania, [Nova York], v. 32, n. 2, p. 198-201, 1949. Disponível em: <https://www.jstor.org/stable/333072>. Acesso em: 13 out. 2021. doi: 10.2307/333072.

[Carta de 18 de dezembro de 1952]. Destinatário: Noonday Press. Seattle, 1952. 1 carta pessoal. Datiloscrito. Caixa 219 da Coleção Farrar, Straus \& Giroux, Inc. Pasta "Machado de Assis General Epitaph of a Small Winner 1953-4".

[Carta de 9 de janeiro de 1953]. Destinatário: Cecil Hemley. Seattle, 1953a. 1 carta pessoal. Datiloscrito. Caixa 219 da Coleção Farrar, Straus \& Giroux, Inc. Pasta "Machado de Assis General Epitaph of a Small Winner 1953-4".

[Carta de 27 de fevereiro de 1953]. Destinatário: Cecil Hemley. Seattle, 1953b. 1 carta pessoal. Datiloscrio. Caixa 219 da Coleção Farrar, Straus \& Giroux, Inc. Pasta "Machado de Assis General Epitaph of a Small Winner 1953-4".

[Carta de 26 de junho de 1953]. Destinatário: Cecil Hemley. Seattle, 1953c. 1 carta pessoal. Datiloscrito. Caixa 219 da Coleção Farrar, Straus \& Giroux, Inc. Pasta "Machado de Assis General Epitaph of a Small Winner 1953-4".

[Carta de $1^{0}$ de outubro de 1953]. Destinatário: Cecil Hemley. Seattle, 1953d. 1 carta pessoal. Cópia datiloscrita. Caixa 219 da Coleção Farrar, Straus \& Giroux, Inc. Pasta "Machado de Assis General Epitaph of a Small Winner 1953-4". . [Carta de 15 de dezembro de 1953]. Destinatário: Cecil Hemley. Seattle, 1953e. 1 carta pessoal. Cópia datiloscrita. Caixa 219 da Coleção Farrar, Straus \& Giroux, Inc. Pasta "Machado de Assis General Epitaph of a Small Winner 1953-4". . [Carta de 23 de dezembro de 1953]. Destinatário: Cecil Hemley. Seattle, 1953f. 1 carta pessoal. Cópia manuscrita. Caixa 219 da Coleção Farrar, Straus \& Giroux, Inc. Pasta "Machado de Assis General Epitaph of a Small Winner 1953-4".

[Carta de 3 de fevereiro de 1954]. Destinatário: Cecil Hemley. Seattle, 1954a. 1 carta pessoal. Cópia datiloscrita. Caixa 219 da Coleção Farrar, Straus \& Giroux, Inc. Pasta "Machado de Assis General Epitaph of a Small Winner 1953-4". 
[Carta de 2 de abril de 1954]. Destinatário: Cecil Hemley. Seattle, 1954b. 1 carta pessoal. Cópia manuscrita. Caixa 219 da Coleção Farrar, Straus \& Giroux, Inc. Pasta "Machado de Assis General Epitaph of a Small Winner 1953-4".

Translator's Preface. In: ASSIS, Machado de; Philosopher or Dog?. Tradução de Clotilde Wilson. Nova York: Noonday Press, 1954c. p. ix-xx. . [Carta de 18 de outubro de 1960]. Destinatário: Robert Wohlforth. Seattle, 1960. 1 carta pessoal. Caixa 600 MssCol979 da Coleção Farrar, Straus \& Giroux, Inc. Pasta "de Assis, M. All Corr. Philosopher or Dog".

. [Carta de 17 de setembro de 1982]. Destinatário: Elizabeth Besobrasow. Seattle, 1982. 1 carta pessoal. Caixa 600 MssCol979 da Coleção Farrar, Straus \& Giroux, Inc. Pasta "de Assis, M. All Corr. Philosopher or Dog".

HÉLIO DE SEIXAS GUIMARÃES é professor livre-docente de literatura brasileira na Universidade de São Paulo e bolsista do CNPq. É autor de Os leitores de Machado de Assis (Nankin/Edusp, 2004) e Machado de Assis, o escritor que nos lê (Editora Unesp, 2017), entre outros livros e artigos.

Orcid: https://orcid.org/0000-0002-2054-2689. E-mail: hsg@usp.br

VINICIUS FERNANDES DE OLIVEIRA é graduando em Letras (Português-Inglês) na Universidade de São Paulo (FFLCH-USP), onde também é bolsista do Programa Unificado de Bolsas (PUB-USP) no projeto "Sobre traduções e internacionalização da obra de Machado de Assis", sob orientação do Prof. Dr. Hélio de Seixas Guimarães.

E-mail: vinis133@usp.br

Recebido: 25.10.2021

Aprovado: 08.11.2021 